\title{
Smoking Cessation in Primary Care: Implementation of a Proactive Telephone Intervention
}

\author{
Cynthia A. McGrath, DNP; ${ }^{1}$ Concetta Zak, DNP; ${ }^{2}$ Kathleen Baldwin, PhD; ${ }^{3}$ \\ M. Nawal Lutfiyya, $\mathrm{PhD}^{4}$
}

\begin{abstract}
${ }^{1}$ Department of Biobehavioral Health Science, College of Nursing, University of Illinois at Chicago, IL, USA; ${ }^{2}$ Associate Dean/Graduate Director, College of Nursing, Lewis University, Romeoville, IL, USA; ${ }^{3}$ Director, Central Illinois Regional Program, College of Nursing, University of Illinois at Chicago, IL, USA; ${ }^{4}$ Essentia Institute of Rural Health, Division of Research, Duluth, MN
\end{abstract}

Running Title: Proactive Telephone Smoking Cessation Intervention

Correspondence to:

Cynthia McGrath, DNP, FNP - BC

Associate Professor

Saint Anthony College of Nursing

5668 East State St.

Rockford, IL, 61108

Phone: 815.979.0372

Email: cmcgrath01@gmail.com.

Word Count: 2,899 


\begin{abstract}
Purpose: To perform a smoking cessation intervention by a nurse practitioner in a primary care setting and assess its effectiveness.

Data Sources: The intervention developed was an operationalization of the 5 As from the U.S. Department of Health and Human Services’ updated Clinical Practice Guideline: Treating Tobacco Use and Dependence. Data were generated from a two-group controlled intervention that compared adult smokers who either received or did not receive an intensive proactive telephone intervention focused on cessation.
\end{abstract}

Conclusions: The intervention group showed movement across stages of change, lower nicotine dependence and increased confidence to quit. Also, 19\% quit smoking and were abstinent at the end of study; none in the control group achieved abstinence. Quit rates were similar to those of other studies. The statistically necessary sample size was not attained, highlighting recruitment difficulties in smoking cessation studies. For a pilot study, the sample size was acceptable. Implications for Practice: Measuring stage of change and nicotine dependence can assist clinicians in implementing cessation strategies. Although effective, a provider may find the intervention too intensive to employ with more than one patient at a time. This intervention should be evaluated with smokers ready to make a quit attempt. 
Introduction

Despite detrimental health effects of smoking and the existence of effective cessation strategies, health professionals are hesitant to discuss smoking cessation due to insufficient time, concern about offending patients, and low confidence in delivering an effective message (Garg et al., 2007; Tong et al., 2010). Clinicians assess smoking status but aren’t comfortable implementing cessation and don’t consistently utilize proven guidelines (Fiore et al., 2008; Tong et al., 2010).

The 2008 updated Clinical Practice Guideline for Tobacco Cessation recommends research to evaluate: cessation interventions given by nurse practitioners; readiness to change; using the telephone as an intervention; and implementing the 5 As (Ask about smoking, Advise the patient to quit in a strong, clear and personalized manner, Assess willingness to attempt quitting, Assist in making a quit attempt, offering support if willing, and Arrange follow-up contact the week after the quit date) (Fiore et al., 2008).

The 2008 Clinical Practice Guideline recommends intensive proactive telephone counseling, problem-solving and support as effective cessation strategies (Fiore et al., 2008). Telephone interventions applied in a variety of health-related situations increase quit rates and are acceptable to patients (Stead, Perera, \& Lancaster, 2009; Tzelepis et al., 2011). Herein is described an evaluation of a proactive telephone intervention that was developed using the 5 As.

This study took place over a three-month period and entailed maintaining contact with adult smokers, focusing on whether or not the intervention moved smokers along the stages of change, increased smoking cessation, and increased quit attempts. Two groups were compared: a control and an intervention group and incorporated the idea that smoking cessation involves two distinct processes: making a quit attempt and maintaining cessation (Brunnhuber et al., 2007). 
The transtheoretical model was the theoretical basis for the study, postulating that behavior change occurs as a non-linear process, in a series of stages, over time (Prochaska, Wright \& Velicer, 2008). Two constructs central to this model are decisional balance (weighting benefits and costs of changing behavior) and self-efficacy (confidence in ability to change). There are 5 transtheoretical stages: Precontemplation (No plan to quit in the next 6 months), Contemplation (Seriously thinking about quitting in the next 6 months OR no prior quit attempt and decided to quit in next 30 days), Preparation (Prior quit attempt in past 12 months and decided to quit in next 30 days), Action (Quit smoking less than 6 months ago), and Maintenance (Quit smoking greater than 6 months ago (Prochaska et al., 2008).

The research question. Are adult patients who smoke more likely to move through the stages of change toward an attempt at smoking cessation when they receive an intensive proactive telephone intervention and written cessation materials in comparison to receiving written cessation materials alone?

Methods

\section{Study Population}

The study population participated in a previous study of adult smokers $(\mathrm{n}=169)$. A power analysis was done (alpha $<.05$, beta .80 ), with effect size of 0.30 (medium effect), yielded that a sample size of 90 would sufficiently power the study. The participant recruitment target was set at 100 to account for attrition. However, this proved to be an unattainable goal despite participants having agreed to participate in the prior study, which included a telephone call. This underscores the challenge in recruiting willing participants in smoking cessation research. This size was acceptable for a pilot study.

Study Design 
This was a two-group controlled intervention pilot study with blinded group assignment. This pilot study compared an evidence-based telephone intervention plus printed smoking cessation guide (intervention group) to printed smoking cessation guide alone (control group) (U.S. Department of Health and Human Service, 2006). Human subject approval was received from the University of Illinois at Chicago College of Medicine at Rockford's IRB.

Initial contact with subjects was made through the mail. All subjects received: an introductory letter explaining the study, smoking cessation guide, consent form, and addressed, stamped envelope. Two weeks after the initial contact, the PI, an N.P., attempted telephone contact with all of the target population to ascertain willingness to participate. People were asked to sign and return the consent form, which had to be received before beginning the intervention.

\section{Intervention}

The Telephone Intervention Guide, implemented by the PI, was drawn from the 5 As (Fiore et al., 2008). Three members of the 2008 Clinical Practice Guideline Panel established content and face validity. The intervention focused on engaging the study participant in reflecting on reasons for smoking, harms inherent in continuing to smoke, challenges faced in quitting and the choice that each cigarette presents of quitting or continuing to smoke. The telephone intervention was delivered by four telephone calls (baseline, 4, 8 and 12 weeks), while the control group received two calls (baseline and 12 weeks) where smoking status and stage of change were measured. For those who elected to make a quit attempt, problem-solving and social support were offered as part of the continued intervention. Social support was operationalized as daily text messaging or telephone calls during the week of the quit attempt.

\section{Outcome Measures}


The primary outcome measures were stage of change and smoking cessation. Secondary outcome measures included quit attempts, self-rating of confidence and motivation to quit, and change in Heaviness of Smoking Index (HIS; Borland et al., 2010). Smoking cessation was defined as continuous abstinence for more than seven days and a quit attempt was defined as 24hour abstinence (Sutton \& Gilbert, 2007).

\section{Measurement Tools}

Three measurement tools were used in the study. The HSI measures nicotine dependence and includes daily cigarette consumption and time to first cigarette ( $<2=$ low; $2-4=$ medium; 56 = high nicotine dependence) (Borland et al., 2010). Stages of change survey measures the current stage of and readiness to change (Wolf et al., 2008). Motivational and self-efficacy scales measure motivation and confidence in quitting on a scale of 1 to 10 determined by answers given to two questions: On a scale of 1 (low) to 10 (high), how motivated are you to quit and how confident are you that you would succeed? (Halterman et al., 2010). Additionally, open-ended questions were asked to encourage problem-solving (Table 1), as recommended by the Guideline (Fiore et al., 2008)

\section{Results}

Data were analyzed descriptively due to small sample size. Out of a possible 169 participants, 72 were not reachable. Thirty-nine people agreed to participate and were randomly assigned to intervention (21) and control (18) groups (Table 2), for a 40.0\% participation rate. Table 1 describes the study participants by group assignment (intervention or control) and covariates (sex, age, self-defined health status, partner status, education and annual household income). 
Smoking history (Table 3) revealed a larger proportion of both groups had been smokers for $>20$ years. Everyone had tried to quit smoking at least once. For the majority of both groups, the longest quit attempt was $\geq 6$ months with the last quit attempt made 6 or more months ago.

At call one, 19\% of the intervention group was highly nicotine-dependent; by call four, none of the intervention group described themselves as highly nicotine-dependent (Table 4). Among controls, there was an increase in those who described themselves as low nicotinedependent between calls one and four.

There was movement across all stages of change in the intervention group between the first and last telephone call (Table 4). At the time of the initial call, 38.1\% of the intervention group was in the pre-contemplation stage, which decreased to $19.0 \%$ by the final call. For the intervention group at call one, $52.4 \%$ were in the contemplation stage, while at call four this had been reduced to $42.9 \%$. Further, those in the preparation stage increased from $9.5 \%$ to $14.3 \%$ by the last call. Finally, none of the intervention participants were in the action stage at call one, while $19.0 \%$ were in the action stage at call four. Among controls, the same proportion stayed in the maintenance stage across all phone calls.

A Likert scale was used to assess motivation and confidence giving up smoking (one meaning not at all motivated or confident and 10 meaning 100\% motivated and confident; Table 5). The responses were re-coded into bifurcated categories, with seven or below re-coded as "less motivated to quit" and eight or above re-coded as "more motivated to quit." The confidence scale was similarly recoded.

The motivation and confidence responses indicated that one-third of the group was more motivated to quit at call one, and by call four, only one-fourth of the group was more motivated to quit. However, four people quit smoking between calls one and four (Table 6). There was an 
increase in confidence, with $28.6 \%$ of the participants gave a number that reflected more confidence at call one and over 50\% of the participants gave a number that reflected more confidence in quitting at call four.

Coding themes were generated from a number of the problem-solving questions asked of the study participants (Table 7). Four themes emerged from the reasons given for smoking relapse: coping with stress, craving, exposure to smoker, and weight control. The majority of respondents from both the groups gave reasons that corresponded with the theme "coping with stress" to describe their smoking relapse. Health concerns such as breathing problems were acknowledged by $50.0 \%$ of the control group, while $33.3 \%$ of the intervention group cited diagnosed disease. A small proportion of each group (22.2\% control, 23.8\% intervention) stated that they had no health concerns.

When describing what they liked about smoking, the control group in almost equal proportions stated habit (38.9\%), stress relief (33.3\%) and nothing (27.8\%), while the majority of the intervention group (57.1\%) cited stress relief. Further, the cost of addiction was reported by over half of the control group as what they most disliked about smoking. In contrast, the largest proportion of the intervention group cited polluting personal environment as what they disliked most about their smoking.

Improving one's health and personal environment was given as the greatest benefit of quitting by the majority of participants in both groups. A small proportion of participants in each group saw no benefit to smoking cessation. For the majority in each group, the greatest challenge of quitting was finding a substitute.

Quitters. Four intervention group participants (19.0\%) quit smoking over the course of this intervention study (Table 6). Length of cessation ranged from 2.5 to 10 weeks of continuous 
cessation. All of the quitters were female. Three of the four quitters were 50 years of age or younger. When self-describing their health, half said they were in excellent to very good health, while the other half reporting good to fair health. One was single, and the others were part of couples. The highest educational attainment for all quitters was high school or less. All but one lived in households with incomes of $\$ 40,000$ or more.

Study participants who quit were more likely to cite an external event as the factor that helped them quit smoking in the past (Table 7). Likewise, they were more likely to claim stress as the reason for past relapse. All but one of the quitters stated that they had health concerns related to smoking. At the time of the initial call, three of the quitters stated that polluting their personal environment was what they disliked most about smoking. Not surprisingly, improving one's health and environment was offered as the main benefit of quitting. Finally, finding a substitution and handling temptation were cited equally as challenges of quitting.

In contrast to the initial call, during the final call to study participants who had quit, one cited improving personal environment as a benefit of quitting, while the other three cited health improvement as the benefit (data not shown). In addition, the study participants who quit articulated their strategies for dealing with cravings as doing something else, such as playing computer games, or tricking themselves by saying “you have just had one” (data not shown).

When comparing the initial and final call to quitters, three of the four quitters had medium nicotine dependence initially, while all four had low nicotine dependence at the final call. Furthermore, all quitters were in the action stage at the final call, having moved from contemplation and preparation at the initial call. Finally, at the last call made to participants who had quit, all were more motivated to stay smoke-free. 
There were a total of seven quit attempts made by five other study participants in the intervention group. These attempts lasted from one day to three weeks. At the time of the final call, these five participants were smoking, having relapsed from a quit attempt during the intervening time. For the intervention group, 18 total quit attempts were made, for a cessation rate of $86 \%$. A member of the control group made one 24-hour quit attempt.

\section{Discussion}

A number of tools measured different dimensions of smokers' experiences and relationships with smoking tobacco, yielding five important findings.

The first important finding was that when measuring readiness to quit with a stage of change survey, there was movement across all stages of change in the intervention group. This movement was less pronounced in the control group, suggesting that the intensive phone intervention encouraged those smokers to move toward a quit attempt. For primary care providers, assessing patients' readiness to change is essential and initiates conversation about smoking cessation between provider and patient. Use of a survey of this nature can be a springboard to assist providers to overcome the discomfort of approaching patients about their smoking (Garg et al., 2007).

The second important finding was that when measuring nicotine dependence by selfreport, there was less dependence at the end of the intervention for those in the intervention group. The HSI (Borland et al., 2010) is another tool for primary care providers to use in their assessment of patients who want to quit. Using this measure would help differentiate between physical and psychological addiction. Prolonged abstention from smoking depends on breaking the psychological or behavioral habituation. Study participants cited finding a substitute and 
handling temptation as among their challenges in quitting smoking. Hence, measuring nicotine dependence on an ongoing basis, as people are moving toward smoking abstinence may provide important direction to providers as they develop individually focused cessation strategies.

The third important finding was that the intervention group demonstrated an increase in confidence to quit smoking over the course of the study. This did not occur for the control group. This suggests that the intervention positively affected the level of confidence of the intervention participants regarding quitting smoking. Because each cessation attempt increases momentum for abstinence, measuring confidence for smoking cessation is an accepted and endorsed component in the treatment of tobacco dependence (Fiore et al., 2008).

The fourth important finding was that the majority of study participants reported having health concerns related to their smoking and acknowledged benefits to quitting. This finding is consistent with research that demonstrates smoking is negatively associated with health-related quality of life (Vogl, Wenig, Leidl, \& Pokhrel, 2012).

Finally, 19\% of the intervention group quit smoking and were abstinent at the end of the study; this was not true for any of the participants in the control group. This rate is well within the quit ranges documented by other studies (Nayan, Gupta \& Sommer, 2011). Furthermore, intervention participants, with an $86 \%$ cessation rate, made 18 total quit attempts. These findings support the chronic nature of cigarette smoking and the difficulty of quitting.

\section{Limitations}

There were three limitations to this study. First, by limiting the target population to participants in a former smoking cessation study, this study was at risk for having a small sample size. As a result, the study was underpowered and could not use analytic statistics. Second, the 
intensity of the intervention was in itself a limitation. Operationalizing the components of the Smoking Cessation Guideline was cumbersome. As a result, the intervention, beyond being intense, required too much time to implement for it to be of practical use in a primary care setting. This is not to suggest that the theoretical concepts individually are not robust, only that when operationalized in the fashion that they were for this intervention, the application was not realistic. No single primary care provider would be able to implement this intervention for more than one patient at a time. Nevertheless, this limitation could not have been revealed without conducting this study. Thus, the study contributes an important thread to the ongoing conversation about time resources in smoking cessation interventions.

Third, the PI for this study managed the intervention for all of the participants as if she were their primary care provider. However, she was not the true primary care provider; thus, the foundational relationship inherent to primary care was absent from this intervention study. This could have impacted the results because of the immediate and temporary nature of the relationship.

\section{Conclusions}

This smoking cessation intervention study undertaken by a nurse practitioner evaluated the effectiveness of advice to quit smoking by a provider other than a physician. In this study, there were people who quit as well as who attempted to quit smoking. The intervention group showed movement across stages of change, lower nicotine dependence, and increased confidence to quit. The quit rates were similar to those of other studies. Research has demonstrated that relapse is both part of the nature of smoking as well as a contributing factor to permanent abstinence. There is value to evaluating this intervention with smokers farther along the stages of change. 


\section{References}

Borland, R., Yong, H. H., O’Connor, R. J., Hyland, A., Thompson, M.E. (2010). The reliability and predictive value of the Heaviness of Smoking Index and its two components: Findings from the International Tobacco Control Four Country study. Nicotine \& Tobacco Research, 12, S45-S50. doi:10.1093/ntr/ntq038

Brunnhuber, K., Cummings, K. M., Feit, S., Sherman, S. \& Woodcock, J. (2007). BMJ Monograph: Putting evidence into practice: smoking cessation. British Medical Journal Publishing Group, Summer 2007, 1-40.

Fiore, M. C., Jaén, C. R., Baker, T. B, Bailey, W. C., Benowitz, N. L., Curry, S. J., et al. (2008). Treating tobacco use and dependence: 2008 update. Clinical Practice Guideline. Rockville, MD: U.S. Department of Health and Human Services. Public Health Service.

Garg, A., Serwint, J., Higman, S., Kanof, A., Schell, D., Colon, I., et al. (2007). Self-efficacy for smoking cessation counseling parents in primary care: An office-based intervention for pediatricians and family physicians. Clinical Pediatrics, 46(3), 252-257.

Halterman, J. S., Borrelli, B., Conn, K. M., Tremblay, P., \& Blaakman, S. (2010). Motivation to Quit Smoking among Parents of Urban Children with Asthma. Patient Education \& Counseling,79(2), 152-155. doi:10.1016/j.pec.2009.09.004

Nayan, S., Gupta, M. K., \& Sommer, D. D. (2011). Evaluating Smoking Cessation Interventions and Cessation Rates in Cancer Patients: A Systematic Review and Meta-Analysis. International Scholarly Research Network Oncology. Published online. doi:10.5402/2011/849023 
Prochaska, J. O., Wright, J. A., \& Velicer, W. F. (2008). Evaluating theories of health behavior change: A hierarchy of criteria applied to the thranstheoretical model. Applied Psychology, 57(4), 561-588. doi:10.1111/j.1464-0597.2008.00345.x

Segan, C. J., Borland, R., Hannan, A. \& Stillman, S. (2008). The challenge of embracing a smoke-free lifestyle: a neglected area in smoking cessation programs. Health Education Research, 23(1), 1-9.

Stead, L. F., Perera, R., \& Lancaster, T. (2009). Telephone counseling for smoking cessation. Cochrane Database of Systematic Reviews. doi:10.1002/14651858.CD002850.pub2.

Sutton, S., \& Gilbert, H. (2007). Effectiveness of individually tailored smoking cessation advice letters as an adjunct to telephone counseling and generic self-help materials: randomized controlled trial. Addiction, 102(6), 994-1000.

Tong, E.K., Strouse, R., Hall, J., Kovac, M., \& Schroeder, S.A. (2010). National survey of U.S. health professionals’ smoking prevalence, cessation practices, and beliefs. Nicotine and Tobacco Research, 12 (7), 724-733. doi:10.1093/ntr/ntq071

Tzelepis, F., Paul, C.L., Walsh, R.A., McElduff, P., \& Knight, J. (2011). Proactive telephone counseling for smoking cessation: Meta-analyses by recruitment channel and methodological quality. Journal of the National Cancer Institute, 103 (12), 922-941. doi:10.1093/jnci/djr169

U.S. Department of Health and Human Service. (2006). You can quit smoking: Consumer guide. Retrieved from http://www.ahrq.gov/consumer/tobacco/quits.pdf

Vogl, M., Wenig, C., Leidl, R., \& Pokhrel, S. (2012). Smoking and health-realted quality of life in English general population: implications for economic evaluations. BMC Public Health, 12(203). doi:10.1186/1471-2458-12-203 
Wolf, R. L., Lepore, S. J., Vandergrift, J. L., Wetmore-Arkader, L., McGinty, E., Pietrzak, G., \& Yaroch, A. L. (2008). Knowledge, Barriers, and Stage of Change as correlates of fruit and vegetable consumption among urban and mostly immigrant black men. Journal of the American Dietetic Association, 108(8), 1315-1322. 


\begin{tabular}{|c|c|c|c|}
\hline \multicolumn{4}{|c|}{ Table 1. Description of Study Participants by Group Assignment } \\
\hline \multicolumn{2}{|c|}{ Variables and Factors } & \multirow{2}{*}{$\begin{array}{c}\begin{array}{c}\text { Control } \\
\mathbf{N}(\%)\end{array} \\
10(55.6 \%)\end{array}$} & \multirow{2}{*}{$\begin{array}{c}\text { Intervention } \\
\text { N (\%) } \\
19(90.5 \%)\end{array}$} \\
\hline Gender & Female & & \\
\hline \multirow{3}{*}{ Age } & Male & $8(44.4 \%)$ & $2(9.5 \%)$ \\
\hline & 50 and Younger & $9(50.0 \%)$ & $11(52.4 \%)$ \\
\hline & Older Than 50 & $9(50.0 \%)$ & $10(47.6 \%)$ \\
\hline \multirow[t]{2}{*}{ Self-Defined Health Status } & Excellent to Very Good Health & $5(27.8 \%)$ & $6(28.6 \%)$ \\
\hline & Good to Fair Health & $13(72.2 \%)$ & $15(71.4 \%)$ \\
\hline \multirow[t]{2}{*}{ Partner Status } & Partnered & $13(72.2 \%)$ & $12(57.1 \%)$ \\
\hline & Not Partnered & $5(27.8 \%)$ & $9(42.9 \%)$ \\
\hline \multirow[t]{2}{*}{ Education } & At Least High School & $12(66.7 \%)$ & $14(66.7 \%)$ \\
\hline & More Than High School & $6(33.3 \%)$ & $7(33.3 \%)$ \\
\hline \multirow[t]{2}{*}{ Annual Household Income } & $\$ 39,999$ or Less & $11(61.1 \%)$ & $9(42.9 \%)$ \\
\hline & $\$ 40,000$ or More & $7(38.9 \%)$ & 12 (57.1\%) \\
\hline
\end{tabular}




\begin{tabular}{|c|c|c|c|}
\hline \multirow{2}{*}{ Variables } & \multirow{2}{*}{ Factors } & \multicolumn{2}{|c|}{ Group } \\
\hline & & $\begin{array}{c}\text { Control } \\
\text { N (\%) }\end{array}$ & $\begin{array}{c}\text { Intervention } \\
\mathbf{N}(\%)\end{array}$ \\
\hline \multirow[t]{2}{*}{ How Long Smoked } & $\leq 20$ Years & $4(22.2 \%)$ & $6(28.6 \%)$ \\
\hline & $>20$ Years & $14(77.8 \%)$ & 15 (71.4\%) \\
\hline Ever Tried Quitting & Yes & $18(100.0 \%)$ & $21(100.0 \%)$ \\
\hline \multirow[t]{2}{*}{ Longest Time Quit } & $<6$ Months & $6(33.3 \%)$ & $8(38.1 \%)$ \\
\hline & $\geq 6$ Months & $12(66.7 \%)$ & $13(61.9 \%)$ \\
\hline \multirow[t]{2}{*}{ Last Quit Attempt } & $<6$ Months Ago & $4(22.2 \%)$ & $1(4.8 \%)$ \\
\hline & $\geq 6$ Months Ago & $14(77.8 \%)$ & 20 (95.2\%) \\
\hline
\end{tabular}




\begin{tabular}{|c|c|c|c|}
\hline \multicolumn{4}{|c|}{ Table 3. Coding Themes for Qualitative Data } \\
\hline \multirow[b]{2}{*}{ Variables } & \multirow[b]{2}{*}{ Factors } & \multicolumn{2}{|c|}{ Group } \\
\hline & & $\begin{array}{c}\text { Control } \\
\text { N (\%) }\end{array}$ & $\begin{array}{c}\text { Intervention } \\
\mathbf{N}(\%)\end{array}$ \\
\hline \multirow{3}{*}{$\begin{array}{l}\text { Help Quit Smoking } \\
\text { Code }\end{array}$} & External Event & $7(38.9)$ & $11(52.4)$ \\
\hline & Internal Decision & $6(33.3)$ & $6(28.6)$ \\
\hline & $\mathrm{Rx}$ & $5(27.8)$ & $4(19.0)$ \\
\hline \multirow[t]{4}{*}{ Smoking Relapse Code } & Coping With Stress & $10(55.6)$ & $13(61.9)$ \\
\hline & Craving & $3(16.7)$ & $3(14.3)$ \\
\hline & Exposure To Smoker & $4(22.2)$ & $4(19.0)$ \\
\hline & Weight Control & $1(5.6)$ & $1(4.8)$ \\
\hline \multirow{2}{*}{$\begin{array}{l}\text { Have Health Concerns } \\
\text { Related to Smoking }\end{array}$} & No & $4(22.2)$ & $5(23.8)$ \\
\hline & Yes & $14(77.8)$ & $16(76.2)$ \\
\hline \multirow[t]{5}{*}{ Health Concerns Code } & Breathing Problems & $9(50.0)$ & $4(19.0)$ \\
\hline & Diagnosed Disease & $4(22.2)$ & $7(33.3)$ \\
\hline & Family History of Cancer & $0(.0)$ & $2(9.5)$ \\
\hline & Know Smoking Bad & $2(11.1)$ & $4(19.0)$ \\
\hline & None & $3(16.7)$ & $4(19.0)$ \\
\hline \multirow{3}{*}{$\begin{array}{l}\text { Like About Smoking } \\
\text { Code }\end{array}$} & Habit & $7(38.9)$ & $7(33.3)$ \\
\hline & Nothing & $5(27.8)$ & $2(9.5)$ \\
\hline & Stress Relief & $6(33.3)$ & $12(57.1)$ \\
\hline \multirow{4}{*}{$\begin{array}{l}\text { Dislike About Smoking } \\
\text { Code }\end{array}$} & Cost Of Addiction & $10(55.6)$ & $4(19.0)$ \\
\hline & Nothing & $1(5.6)$ & $1(4.8)$ \\
\hline & Polluting Personal Environment & $6(33.3)$ & $14(66.7)$ \\
\hline & Stigma & $1(5.6)$ & $2(9.5)$ \\
\hline \multirow{3}{*}{$\begin{array}{l}\text { Benefits of Quitting } \\
\text { Code }\end{array}$} & Improve Health and Personal Environment & $13(72.2)$ & $14(66.7)$ \\
\hline & No Benefit & $2(11.1)$ & $2(9.5)$ \\
\hline & Save Money & $3(16.7)$ & $5(23.8)$ \\
\hline \multirow{3}{*}{$\begin{array}{l}\text { Challenges of Quitting } \\
\text { Code }\end{array}$} & Avoiding Weight Gain & $1(5.6)$ & $4(19.0)$ \\
\hline & Finding Substitution & $13(72.2)$ & $10(47.6)$ \\
\hline & Handling Temptation & $4(22.2)$ & $7(33.3)$ \\
\hline
\end{tabular}




\begin{tabular}{|c|c|c|c|c|c|}
\hline \multicolumn{6}{|c|}{$\begin{array}{l}\text { Table 4. Comparison between Call } 1 \text { and Call } 4 \text { of Nicotine Dependence and } \\
\text { Stages of Change by Group Status }\end{array}$} \\
\hline \multirow[t]{2}{*}{ Measure } & \multirow[t]{2}{*}{ Scale Items } & \multicolumn{2}{|c|}{ Group Call 1} & \multicolumn{2}{|c|}{ Group Call 4} \\
\hline & & $\begin{array}{c}\text { Control } \\
\mathrm{N}(\%)\end{array}$ & $\begin{array}{l}\text { Intervention } \\
\qquad \mathrm{N}(\%)\end{array}$ & $\begin{array}{c}\text { Control } \\
\mathrm{N}(\%)\end{array}$ & $\begin{array}{c}\text { Intervention } \\
\mathrm{N}(\%)\end{array}$ \\
\hline \multirow[t]{3}{*}{$\begin{array}{l}\text { Heaviness of } \\
\text { Smoking Index }\end{array}$} & $\begin{array}{l}\text { Low Nicotine } \\
\text { Dependence }\end{array}$ & $6(33.3 \%)$ & $5(23.8 \%)$ & $9(50.0 \%)$ & $5(31.3 \%)$ \\
\hline & $\begin{array}{l}\text { Medium Nicotine } \\
\text { Dependence }\end{array}$ & $8(44.4 \%)$ & $12(57.1 \%)$ & $7(38.9 \%)$ & 11 (68.8\%) \\
\hline & $\begin{array}{l}\text { High Nicotine } \\
\text { Dependence }\end{array}$ & $4(22.2 \%)$ & $4(19.0 \%)$ & $2(11.1 \%)$ & $0(0.0 \%)$ \\
\hline \multirow[t]{5}{*}{ Stages of Change } & Pre-contemplation & $5(27.8 \%)$ & $8(38.1 \%)$ & $3(16.7 \%)$ & $4(19.0 \%)$ \\
\hline & Contemplation & $10(55.6 \%)$ & $11(52.4 \%)$ & $9(50.0 \%)$ & $9(42.9 \%)$ \\
\hline & Preparation & $1(5.6 \%)$ & $2(9.5 \%)$ & $3(16.7 \%)$ & $3(14.3 \%)$ \\
\hline & Action & & & $1(5.6 \%)$ & $4(19.0 \%)$ \\
\hline & Maintenance & $2(11.1 \%)$ & $0(0.0 \%)$ & $2(11.1 \%)$ & $0(0.0 \%)$ \\
\hline
\end{tabular}




\begin{tabular}{|c|c|c|c|c|c|c|c|c|c|c|c|c|c|c|c|c|}
\hline \multicolumn{17}{|c|}{ Table 5. Comparison of Intervention Group Motivation and Confidence to Quit by Number of Call } \\
\hline Scale & \multicolumn{4}{|c|}{ Call 1} & \multicolumn{4}{|c|}{ Call 2} & \multicolumn{4}{|c|}{ Call 3} & \multicolumn{4}{|c|}{ Call 4} \\
\hline \multirow[t]{3}{*}{$\begin{array}{c}\text { Motivated to } \\
\text { Quit Scale }\end{array}$} & \multicolumn{2}{|c|}{$\begin{array}{c}\text { Less } \\
\text { Motivated To } \\
\text { Quit }\end{array}$} & \multicolumn{2}{|c|}{$\begin{array}{c}\text { More } \\
\text { Motivated To } \\
\text { Quit }\end{array}$} & \multicolumn{2}{|c|}{$\begin{array}{c}\text { Less } \\
\text { Motivated To } \\
\text { Quit }\end{array}$} & \multicolumn{2}{|c|}{$\begin{array}{c}\text { More } \\
\text { Motivated To } \\
\text { Quit }\end{array}$} & \multicolumn{2}{|c|}{$\begin{array}{c}\text { Less } \\
\text { Motivated To } \\
\text { Quit }\end{array}$} & \multicolumn{2}{|c|}{$\begin{array}{c}\text { More } \\
\text { Motivated To } \\
\text { Quit }\end{array}$} & \multicolumn{2}{|c|}{$\begin{array}{c}\text { Less } \\
\text { Motivated To } \\
\text { Quit }\end{array}$} & \multicolumn{2}{|c|}{$\begin{array}{c}\text { More } \\
\text { Motivated To } \\
\text { Quit }\end{array}$} \\
\hline & $\mathrm{N}$ & $\%$ & $\mathrm{~N}$ & $\%$ & $\mathrm{~N}$ & $\%$ & $\mathrm{~N}$ & $\%$ & $\mathrm{~N}$ & $\%$ & $\mathrm{~N}$ & $\%$ & $\mathrm{~N}$ & $\%$ & $\mathrm{~N}$ & $\%$ \\
\hline & 14 & 66.7 & 7 & 33.3 & 16 & 88.9 & 2 & 11.1 & 14 & 87.5 & 2 & 12.5 & 11 & 73.3 & 4 & 26.7 \\
\hline \multirow[t]{3}{*}{$\begin{array}{l}\text { Confidence } \\
\text { to Quit Scale }\end{array}$} & \multicolumn{2}{|c|}{$\begin{array}{c}\text { Less } \\
\text { Confidence In } \\
\text { Quitting } \\
\end{array}$} & \multicolumn{2}{|c|}{$\begin{array}{c}\text { More } \\
\text { Confidence In } \\
\text { Quitting } \\
\end{array}$} & \multicolumn{2}{|c|}{$\begin{array}{c}\text { Less } \\
\text { Confidence } \\
\text { In Quitting } \\
\end{array}$} & \multicolumn{2}{|c|}{$\begin{array}{c}\text { More } \\
\text { Confidence In } \\
\text { Quitting } \\
\end{array}$} & \multicolumn{2}{|c|}{$\begin{array}{c}\text { Less } \\
\text { Confidence } \\
\text { In Quitting } \\
\end{array}$} & \multicolumn{2}{|c|}{$\begin{array}{c}\text { More } \\
\text { Confidence In } \\
\text { Quitting } \\
\end{array}$} & \multicolumn{2}{|c|}{$\begin{array}{c}\text { Less } \\
\text { Confidence In } \\
\text { Quitting } \\
\end{array}$} & \multicolumn{2}{|c|}{$\begin{array}{c}\text { More } \\
\text { Confidence In } \\
\text { Quitting } \\
\end{array}$} \\
\hline & $\mathrm{N}$ & $\%$ & $\mathrm{~N}$ & $\%$ & $\mathrm{~N}$ & $\%$ & $\mathrm{~N}$ & $\%$ & $\mathrm{~N}$ & $\%$ & $\mathrm{~N}$ & $\%$ & $\mathrm{~N}$ & $\%$ & $\mathrm{~N}$ & $\%$ \\
\hline & 15 & 71.4 & 6 & 28.6 & 10 & 52.6 & 9 & 47.4 & 9 & 56.3 & 7 & 43.8 & 7 & 43.8 & 9 & 56.3 \\
\hline
\end{tabular}




\begin{tabular}{|l|l|c|c|}
\hline \multicolumn{4}{|c|}{ Table 6. Description of Quitters } \\
\hline \multirow{2}{*}{ Variables and Factors } & Frequency & Percent \\
\hline \multirow{2}{*}{ Age } & Female & 4 & 100.0 \\
\hline \multirow{2}{*}{ Self-defined Health } & 50 And Younger & 3 & 75.0 \\
\cline { 2 - 4 } & Older Than 50 & 1 & 25.0 \\
\cline { 2 - 4 } & Excellent To Very Good Health & 2 & 50.0 \\
\cline { 2 - 4 } Partner Status & Good To Fair Health & 2 & 50.0 \\
\cline { 2 - 4 } & Coupled & 3 & 75.0 \\
\hline \multirow{2}{*}{ Education } & Single & 4 & 25.0 \\
\hline \multirow{2}{*}{ Household Income } & High School Or Less & 1 & 100.0 \\
\cline { 2 - 4 } & $\$ 39,999$ Or Less & 3 & 25.0 \\
\cline { 2 - 4 } & $\$ 40,000$ Or More & 45.0 \\
\hline
\end{tabular}




\begin{tabular}{|c|c|c|c|}
\hline \multicolumn{4}{|c|}{ Table 7. Coding Themes for Qualitative Data for Quitters for Call 1} \\
\hline \multicolumn{2}{|c|}{ Variables and Factors } & Frequency & Percent \\
\hline \multirow[t]{2}{*}{ Help Quit Smoking Code } & External Event & 3 & 75.0 \\
\hline & $\mathrm{Rx}$ & 1 & 25.0 \\
\hline \multirow[t]{2}{*}{ Smoking Relapse Code } & Coping with Stress & 3 & 75.0 \\
\hline & Exposure to Smoker & 1 & 25.0 \\
\hline \multirow{2}{*}{$\begin{array}{l}\text { Have Health Concerns } \\
\text { Related to Smoking }\end{array}$} & No & 1 & 25.0 \\
\hline & Yes & 3 & 75.0 \\
\hline \multirow[t]{3}{*}{ Health Concerns Code } & Breathing Problems & 1 & 25.0 \\
\hline & None & 1 & 25.0 \\
\hline & Diagnosed Disease & 2 & 50.0 \\
\hline \multirow[t]{3}{*}{ Like About Smoking Code } & Habit & 1 & 25.0 \\
\hline & Nothing & 1 & 25.0 \\
\hline & Stress Relief & 2 & 50.0 \\
\hline \multirow{2}{*}{$\begin{array}{l}\text { Dislike About Smoking } \\
\text { Code }\end{array}$} & Cost Of Addiction & 1 & 25.0 \\
\hline & Polluting Personal Environment & 3 & 75.0 \\
\hline Benefits of Quitting Code & Improve Health and Environment & 4 & 100.0 \\
\hline \multirow[t]{2}{*}{ Challenges of Quitting } & Finding Substitution & 2 & 50.0 \\
\hline & Handling Temptation & 2 & 50.0 \\
\hline
\end{tabular}




\begin{tabular}{|l|l|c|c|}
\hline \multicolumn{4}{|c|}{ Table 8. Comparison of Quitters By Initial and Final Call } \\
\hline \multirow{3}{*}{ HSI Score } & $\begin{array}{c}\text { First Call } \\
\text { N (\%) }\end{array}$ & $\begin{array}{c}\text { Final Call } \\
\text { N (\%) }\end{array}$ \\
\cline { 2 - 4 } & Low Nicotine Dependence & $1(25)$ & $4(100)$ \\
\hline \multirow{3}{*}{ Stages Of Change } & Medium Nicotine Dependence & $3(75)$ & \\
\cline { 2 - 4 } & Contemplation & $2(50)$ & \\
\cline { 2 - 4 } & Preparation & $2(50)$ & $4(100)$ \\
\hline \multirow{2}{*}{ Confidence Scale } & Action & $1(25)$ & $2(50)$ \\
\cline { 2 - 4 } & Lese Confidence In Quitting & $3(75)$ & $2(50)$ \\
\hline \multirow{3}{*}{ Motivation Scale } & More Motivated To Quit & $3(75)$ & $4(100)$ \\
\cline { 2 - 4 } & Less Motivated To Quit & $1(25)$ & \\
\hline
\end{tabular}

